\title{
Sol-Gel Production and XPS Study of Sodium-Vanadium Oxide Bronze $\beta$-Phase
}

\author{
V. Bondarenka ${ }^{a, b}$, H. Tvardauskas ${ }^{a}$, M. Senulis $^{a}$, A. PašišKeviČiuss ${ }^{a}$, S. Grebinskij $^{a}$, \\ S. MiCKEVIČIUS ${ }^{a}$ AND I. VITKUTE் $\dot{E}^{b}$ \\ ${ }^{a}$ Semiconductor Physics Institute, Centre for Physical Sciences and Technology \\ A. Goštauto 11, LT-01108 Vilnius, Lithuania \\ ${ }^{b}$ Vilnius Pedagogical University, Studentu̧ 39, LT-08106 Vilnius, Lithuania
}

\begin{abstract}
A $\beta$-phase of sodium-vanadium oxide bronze thin film has been synthesized by using sol-gel technology from $\mathrm{V}_{2} \mathrm{O}_{5}$ and $\mathrm{Na}_{2} \mathrm{SO}_{4}$. The powders of these materials in suitable proportion were dissolved in hydrogen peroxide and heated up to $350 \mathrm{~K}$ for the dissociation of peroxide complexes. The obtained gel was deposited onto a metallic substrate and dried in air at room temperature. The produced xerogel was heated up to $580 \mathrm{~K}$ in air atmosphere for the removal of water from xerogel. Starting materials, xerogel, as well as a final product were investigated by means of X-ray photoelectron spectroscopy method. X-ray photoelectron spectra testify that the chemical bonds of vanadium, oxygen and sodium in the bronze differ from the similar bonds in the starting materials. The sulphur presence was detected in the xerogel but not in the final bronze composition.
\end{abstract}

PACS: 68.47.Gh, 81.20.Fw, 82.80.Pv

\section{Introduction}

The interest to the vanadium compounds strongly increased during last years, when a phase transition in the sodium-vanadium oxide bronze $\alpha^{\prime}-\mathrm{NaV}_{2} \mathrm{O}_{5}$ was observed [1]. This bronze is an inorganic material considered to exhibit the spin-Peierls transition. The last fact excites interest to the charge ordering investigations in vanadium oxide bronzes $\mathrm{Me}_{x} \mathrm{~V}_{2} \mathrm{O}_{5}(\mathrm{Me}=$ alkali, alkali earth, metal). These materials are mixed-valence oxides and their physical-chemical properties depend on the nature of Me and its atomic concentration [2]. The bulk or powder bronzes can be synthesized by using solid-state chemical reactions or hydrothermal methods $[3,4]$. Thin films of the bronzes can be prepared by using thermal evaporation of needed compounds [5]. All above described methods demand application of high-temperature and some special equipment. More usable method for the thin films production is sol-gel synthesis, when vanadium oxide based compounds are given from aqueous precursors [6]. The bronze $\alpha^{\prime}-\mathrm{NaV}_{2} \mathrm{O}_{5}$ was synthesized by using sol-gel technology [7].

The aim of present work was to produce the $\beta$-phase of sodium-vanadium oxide bronze $\left(\mathrm{Na}_{0.33} \mathrm{~V}_{2} \mathrm{O}_{5}\right)$ by using sol-gel method and X-ray photoelectron spectroscopy (XPS) study of the valence state of vanadium ions.

\section{Experimental}

$\mathrm{V}_{2} \mathrm{O}_{5}$ and $\mathrm{Na}_{2} \mathrm{SO}_{4}$ powders in the suitable proportion were dissolved in $10 \% \mathrm{H}_{2} \mathrm{O}_{2}$ at $273 \mathrm{~K}$. Then the solution was heated up to $333 \mathrm{~K}$ for the dissociation of the peroxide compounds. Produced gel was deposited on $\mathrm{Ni}$ substrate and dried in air at room temperature. Obtained xerogel of a dark-brown color was heated up to $580 \mathrm{~K}$ in air atmosphere for $2 \mathrm{~h}$ for the water removal from the xerogel. After this treatment, the color of the films changed from dark-brown to dark-green.

XSAM 800 spectrometer (Kratos Analytical, UK) was used to record the X-ray photoelectron spectra. During the spectrum analysis the working pressure was below $10.7 \mathrm{~Pa}$ in the analysis chamber. Using KRATOS DS800 data system the photoemission data has been collected and processed. The multiple photoelectron spectra were separated into several peaks setting the peak position: binding energy (BE), area (A), width (FWHM), and Gaussian/Lorentzian $(\mathrm{G} / \mathrm{L})$ ratio, after the $\mathrm{Mg} K_{\alpha}$ source satellites and background deduction. The random $\mathrm{C} 1 s$ line the BE of which should have been equal to $284.6 \mathrm{eV}$ was used for the correction of the charging effects. After the Shirley background subtraction, a non-linear least squares curve fitting routine was used for the analysis of XPS spectra.

XPS spectra were measured for starting materials $\left(\mathrm{V}_{2} \mathrm{O}_{5}\right.$ and $\mathrm{Na}_{2} \mathrm{SO}_{4}$ powders) as well as for vanadium-sodium oxide xerogel and bronze (after heat treatment).

\section{Results and discussion}

Figure 1 reports the comparison spectra of the vanadium-oxygen region of the xerogel (1) and bronze (2). It is clear that the main changes are in $\mathrm{O} 1 \mathrm{~s}$ peak that can be connected with the water removal from the xerogel after the heat treatment. The results of 
the detailed investigation of all measured compounds are summarized in Table, where the binding energy values of the main XPS peaks are presented. The binding energies of $\mathrm{V} 2 p_{3 / 2}, \mathrm{~V} 2 p_{1 / 2}$ and $\mathrm{O} 1 s$ peaks of $\mathrm{V}_{2} \mathrm{O}_{5}$ are typical for vanadium pentoxide [8]. $\mathrm{Na} 1 s, \mathrm{~S} 2 p_{3 / 2}$ and $\mathrm{O} 1 s$ binding energies of $\mathrm{Na}_{2} \mathrm{SO}_{4}$ are similar as reported for sodium-sulphur-oxygen compounds [9]. V $2 p_{3 / 2}$ and $\mathrm{V} 2 p_{1 / 2}$ peaks of bronze and xerogel consists of two components which corresponds to $\mathrm{V}^{4+}$ and $\mathrm{V}^{5+}$ ions [8]. O $1 s$ peak of xerogel consists of three components which corresponds to $\mathrm{O}^{2-},(\mathrm{OH})^{-}$and $\mathrm{H}_{2} \mathrm{O}[10,11]$. O $1 s$ peak in the bronze consists only of one component - $\mathrm{O}^{2-}$ ions. Last fact means that after the heat treatment of the xerogel all water and hydroxile groups were removed, i.e. the vanadium-sodium oxide bronze was formed. The presence of sulphur in the xerogel and bronze was not detected. Quantitative analysis shows that the composition of the bronze is $\mathrm{Na}_{0.35} \mathrm{~V}_{2} \mathrm{O}_{4.96}$.

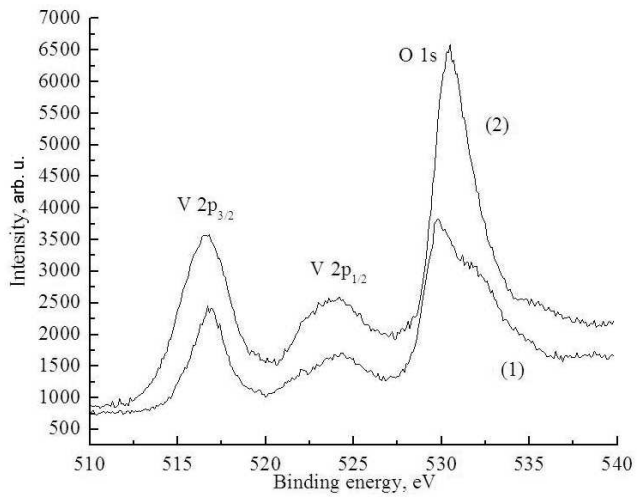

Fig. 1. Overlap spectrum of vanadium-sodium oxide xerogel (1) and bronze (2).

Binding energies of the main XPS peaks for starting materials $\left(\mathrm{V}_{2} \mathrm{O}_{5}, \mathrm{Na}_{2} \mathrm{SO}_{4}\right)$,

TABLE xerogel and bronze.

\begin{tabular}{c|c|c|c|c|c|c|c}
\hline \hline \multirow{2}{*}{ Sample } & \multicolumn{2}{|c|}{$\mathrm{V} 2 p_{3 / 2}$} & \multicolumn{2}{|c|}{$\mathrm{V} 2 p_{1 / 2}$} & \multirow{2}{*}{$\mathrm{O} 1 s$} & \multirow{2}{*}{$\mathrm{Na} 1 s$} & \multirow{2}{*}{$\mathrm{S} 2 p_{3 / 2}$} \\
\cline { 2 - 5 } & $\mathrm{V}^{4+}$ & $\mathrm{V}^{5+}$ & $\mathrm{V}^{4+}$ & $\mathrm{V}^{5+}$ & & & - \\
\hline $\mathrm{V}_{2} \mathrm{O}_{5}$ & - & 517.1 & - & 524.9 & 530.8 & - & - \\
$\mathrm{Na}_{2} \mathrm{SO}_{4}$ & - & - & - & - & 531.6 & 1071.5 & 168.8 \\
xerogel & 516.2 & 516.98 & 522.8 & 524.6 & $529.8\left(\mathrm{O}^{2-}\right)$ & 1071.34 & - \\
& & & & & $531.7\left(\mathrm{OH}^{-}\right)$ & & \\
& & & & & $533.5\left(\mathrm{H}_{2} \mathrm{O}\right)$ & & \\
bronze & 515.7 & 516.9 & 522.8 & 524.6 & $530.6\left(\mathrm{O}^{2-}\right)$ & 1071.35 & -
\end{tabular}

\section{Conclusion}

The results of the present work convincingly shows that the methods of the sol-gel technology allows to produce the vanadium oxide bronzes without using the special technological equipment.

\section{References}

[1] M. Isobe, Y. Ueda, J. Phys. Soc. Jpn. 65, 1178 (1966).

[2] M. Iton, A. Akimoto, M. Tsuchiya, H. Yamada, M. Isobe, Y. Ueda, Physica B 281-282, 606 (2000).

[3] P. Hagenmuller, J. Galy, M. Pouchard, A. Casalot, Mater. Res. Bull. 1, 95 (1966).

[4] F. Zhang, P. Zavalij, M.S. Whittingham, Electrochem. Commun. 1, 564 (1999).

[5] A. Cesnys, V. Bondarenka, A. Oginskis, A. Latyshenka, V. Lisauskas, J. Solid State Chem. 113, 438 (1994).
[6] J. Livage, Coord. Chem. Rev. 178-180, 999 (1998).

[7] V. Bondarenka, Z. Martunas, S. Kaciulis, L. Pandolfi, J. Electron Spectrosc. Relat. Phenom. 131-132, 99 (2003).

[8] V. Bondarenka, S. Grebinskij, S. Mickevicius, H. Tvardauskas, S. Kaciulis, J. Alloys Comp. 382, 239 (2004).

[9] D. Briggs, M.P. Seah, Practical Surface Analysis, Vol. 1, Wiley, New York 1990.

[10] D. Borgmann, E. Hums, G. Hopfengartner, G. Welder, G.W. Spitznagel, I. Rademacher, J. Electron Spectrosc. Relat. Phenom. 63, 91 (1993).

[11] B. Brox, I. Olefjord, U. Jelvestam, J. Electrochem. Soc. 132, 2854 (1985). 